\title{
Otomasi dan Optimasi Pengaturan Kerja pada Pondok Pesantren Menggunakan Profile Matching
}

\author{
Mokh Nugroho Ardhi' ${ }^{1}$ Annisa Dinar Farazizah ${ }^{2}$, Fatmawati Hanifah Firza ${ }^{3}$, Muhammad Ainul \\ Yaqin ${ }^{4}$ \\ Jurusan Teknik Infromatika, Fakultas Sains dan Teknologi Universitas Islam Negeri Maulana Malik \\ Ibrahim Malang \\ Jalan Gajayana No. 50 Malang 65144 Telp. +62(341) 551-354 \\ 16650062@student.uin-malang.ac.id ${ }^{1}$,16650065@student.uin-malang.ac.id ${ }^{2}$, \\ 16650120@student.uin-malang.ac.id ${ }^{3}$, yaqinov@ti.uin-malang.ac.id ${ }^{4}$
}

\begin{abstract}
Islamic boarding schools are religious institutions that provide education and teaching and develop and spread Islam. As an institution, Islamic boarding schools have many activities in them. In each activity requires an organizational structure to manage activities so that they are carried out properly. The process of selecting the person in charge is generally directly chosen by the board but this has both positive and negative sides. The positive side shortens the time in the election because there is no selection in determining the person responsible. The negative side of the direct appointment process is that it cannot see the abilities possessed by the candidates in charge of leadership, organization, and so on. This can only be known with the selection process, what often happens is the selection of the person in charge who does not have the appropriate ability. Under these circumstances, we need a system that can help boarding school administrators in facilitating the selection and appointment of the person in charge. In this study, profile matching is used to calculate the compatibility of the profile of the work and the profile of the person in charge. Each person in charge who is sought has each criterion consisting of core factors and secondary factors. The results obtained from this study are decision support systems that produce responsible recommendations in accordance with the criteria for each activity in the boarding school.
\end{abstract}

Keywords: Sistem Pendukung Keputusan, profile matching, core factor, secondary factor.

\begin{abstract}
Abstrak
Pondok pesantren adalah lembaga keagamaan yang memberikan pendidikan dan pengajaran serta mengembangkan dan menyebarkan agama Islam. Sebagai lembaga, pondok pesantren memiliki banyak kegiatan di dalamnya. Dalam setiap kegiatan membutuhkan struktur organisasi untuk memanajemen kegiatan agar terlaksana dengan baik. Proses pemilihan penanggung jawab pada umumnya dipilih langsung oleh pengurus tetapi hal ini memiliki sisi positif dan sisi negatif. Sisi positifnya mempersingkat waktu dalam pemilihan karena tidak adanya seleksi dalam menentukan penanggung jawab. Sisi negatifnya dari proses penunjukan langsung adalah tidak bisa melihat kemampuan yang dimiliki oleh calon kandidat penanggung jawab baik itu kemampuan kepemimpinan, organisasi dan lain sebagainya. Hal ini hanya bisa diketahui dengan adanya proses seleksi, hal yang sering terjadi adalah terpilihnya penanggung jawab yang tidak memiliki kemampuan yang sesuai. Berdasarkan keadaan tersebut, maka diperlukan suatu sistem yang dapat membantu pengurus pondok pesantren dalam mempermudah pemilihan dan penunjukan penanggung jawab. Dalam penelitian ini digunakan profile matching untuk menghitung kecocokan profil dari pekerjaan dan profil dari penanggung jawab. Setiap penanggung jawab yang dicari memiliki kriteria masing-masing yang terdiri dari core factor dan secondary factor. Hasil yang diperoleh dari penelitian ini adalah sistem pendukung keputusan yang menghasilkan rekomendasi penanggung jawab yang sesuai dengan kriteria pada setiap kegiatan yang ada di pondok pesantren.
\end{abstract}

Kata kunci: Sistem Pendukung Keputusan, profile matching, core factor, secondary factor. 
https://tunasbangsa.ac.id/ejurnal/index.php/jurasik

\section{PENDAHULUAN}

Pondok pesantren adalah lembaga keagamaan yang memberikan pendidikan dan pengajaran serta mengembangkan dan menyebarkan ilmu agama Islam. Sebagai lembaga, pondok pesantren memiliki banyak pekerjaan di dalamnya. Dalam setiap pekerjaan membutuhkan penanggung jawab untuk memanajemen kegiatan agar terlaksana dengan baik. Dalam praktiknya pengaturan kerja yang ada di pondok pesantren belum terlaksana dengan baik dikarenakan sumber daya manusia yang ada belum memenuhi spesifikasi dari suatu pekerjaan. Penyebab hal ini bisa terjadi adalah sumber daya manusia yang bersangkutan mengalami overload tugas atau penugasan pekerjaan tidak sesuai dengan kebutuhan. Berdasarkan situasi tersebut, ditemukan masalah yaitu perlu adanya mekanisme otomasi dan optimasi yang mengatur pengaturan kerja agar pekerjaan yang ada terlaksana dengan optimal. Optimasi merupakan cara yang dilakukan untuk memberikan hasil yang terbaik yang diinginkan. Beberapa metode optimasi [1-3] yang sering digunakan yaitu Simple Additive Weighting (SAW), Weighted Product (WP), dan Profile Matching. Semua metode tersebut hasil akhirnya berupa perangkingan dari proses perhitungan yang telah ditentukan.

Metode optimasi yang digunakan untuk pengaturan kerja di pondok pesantren adalah Profile Matching. Metode Profile Matching dapat mencari pekerja yang sesuai dengan pekerjaan yang ada dari spesifikasi yang telah ditentukan. Metode ini dipilih karena mampu menyeleksi alternatif terbaik dari sejumlah alternatif, dalam hal ini alternatif yang dimaksudkan yaitu yang layak menjadi penanggung jawab dari pekerjaan yang ada. Penelitian dilakukan dengan menentukan aspek, serta mencari nilai bobot untuk setiap aspek, mencari GAP antara profil dengan keadaan data dari pekerja. Dengan menggunakan metode ini, ditentukan persentase kedua unsur aspek dan ditotal, kemudian dilakukan proses perangkingan yang akan menentukan alternatif yang optimal, yaitu penanggung jawab terbaik untuk setiap pekerjaan. Pemilihan metode ini juga didasarkan pada spesifikasi dari pekerjaan dan spesifikasi dari pekerja yang akan dicocokan. Tujuan dari penelitian ini adalah pengaturan kerja yang otomatis dan optimal sehingga pekerjaan yang ada di pondok pesantren dapat terlaksana dengan baik.

\section{METODOLOGI PENELITIAN}

\subsection{Proses Pengambilan Keputusan}

Menurut Richard et.all dalam [4] menjabarkan bahwa dalam pengambilan keputusan terdiri atas 6 proses seperti berikut.

a. Observasi, tahap ini berupa aktifitas atau proses kunjungan lapangan, konferensi, observasi, dan riset yang dapat menjadi informasi dan data penunjang.

b. Analisis dan pengenalan masalah, tahap ini dapat berupa penentuan penggunaan, penentuan tujuan, dan penentuan batasan-batasan yang dapat menjadi pedoman atau petunjuk yang jelas untuk mencari pemecahan masalah yang dibutuhkan. 
c. Pengembangan model, tahapan ini menentukan peralatan pengambilan keputusan antar hubungan model matematika, riset yang dapat menjadi output proses.

d. Memilih data masukan yang sesuai, tahapan ini dapat berupa data internal dan eksternal, kenyataan, pendapat, serta database berbasis komputer yang dapat digunakan untuk menguji model yang digunakan.

e. Perumusan dan pengujian, tahapan ini berupa pengujian, dan pembuktian yang dapat menjadi pemecahan yang membantu pencapaian tujuan.

f. Penerapan pemecahan, tahap ini berupa pembahasan perilaku, pelontaran ide, pelibatan manajemen, serta penjelasan yang menjadi pemahaman manajemen untuk menunjang model operasi dalam jangka yang lebih panjang.

\subsection{Profile Matching}

Metode profile matching atau pencocokan profil adalah metode yang sering digunakan sebagai mekanisme dalam pengambilan keputusan dengan mengasumsikan bahwa terdapat tingkat variabel prediktor yang ideal yang harus dipenuhi oleh subyek yang diteliti, bukannya tingkat minimal yang harus dipenuhi atau dilewati [5]. Berikut adalah beberapa tahapan dan perumusan perhitungan dengan metode profile matching:

\section{a) Pembobotan}

Pada tahap ini, akan ditentukan bobot nilai masing-masing aspek dengan menggunakan bobot gap.

Tabel 1. Bobot Gap

\begin{tabular}{|c|c|l|}
\hline Selisih & $\begin{array}{c}\text { Bobot } \\
\text { Nilai }\end{array}$ & \multicolumn{1}{|c|}{ Keterangan } \\
\hline 0 & 5 & $\begin{array}{l}\text { Tidak ada selisih (kompetensi sesuai dgn yg } \\
\text { dibutuhkan) }\end{array}$ \\
\hline 1 & 4,5 & Kompetensi individu kelebihan 1 tingkat \\
\hline-1 & 4 & Kompetensi individu kekurangan 1 tingkat \\
\hline 2 & 3,5 & Kompetensi individu kelebihan 2 tingkat \\
\hline-2 & 3 & Kompetensi individu kekurangan 2 tingkat \\
\hline 3 & 2.5 & Kompetensi individu kelebihan 3 tingkat \\
\hline-3 & 2 & Kompetensi individu kekurangan 3 tingkat \\
\hline 4 & 1,5 & Kompetensi individu kelebihan 4 tingkat \\
\hline-4 & 1 & Kompetensi individu kekurangan 4 tingkat \\
\hline
\end{tabular}

\section{b) Pengelompokan Core dan Secondary Factor}

Setelah menentukan bobot nilai gap kriteria yang dibutuhkan, tiap kriteria dikelompokkan menjadi dua kelompok yaitu core factor dan secondary factor.

1) Core Factor (Faktor Utama)

Core factor merupakan aspek (kompetensi) yang menonjol/paling dibutuhkan. Untuk menghitung core factor digunakan rumus: 


$$
N C F=\frac{\sum N C}{\sum I C}
$$

Keterangan :

$\mathrm{NCF}=$ Nilai rata- rata core factor

$\Sigma \mathrm{NC}=$ Jumlah total nilai core factor

$\Sigma I C=$ Jumlah item core factor

2) Secondary Factor (Faktor Pendukung)

Secondary factor adalah item-item selain aspek yang ada pada core factor. Untuk menghitung secondary factor digunakan rumus:

$$
N S F=\frac{\sum N S}{\sum I S}
$$

Keterangan :

NSF = Nilai rata- rata secondary factor

$\Sigma \mathrm{NS}=$ Jumlah total nilai secondary factor

$\Sigma$ IS = Jumlah item secondary factor

\section{c) Perhitungan Nilai Total}

Dari perhitungan core factor dan secondary factor dari tiap-tiap aspek, kemudian dihitung nilai total dari tiap-tiap aspek yang diperkirakan berpengaruh pada kinerja tiap-tiap profil. Untuk menghitung nilai total dari masing-masing aspek, digunakan rumus:

$$
\mathrm{N}=(\mathrm{X}) \% \mathrm{NCF}+(\mathrm{X}) \% \mathrm{NSF}
$$

Keterangan :

$\mathrm{N}=$ Nilai total tiap aspek

$\mathrm{NCF}=$ Nilai rata-rata core factor

$\mathrm{NSF}=$ Nilai rata-rata secondary factor

$(\mathrm{X}) \%=$ Nilai persentase yang diinputkan

\section{d) Perankingan}

Hasil akhir dari proses profile matching adalah ranking yang mengacu pada hasil perhitungan yang ditunjukan oleh rumus:

Ranking $=60 \% \mathrm{NCF}+40 \% \mathrm{NSF}$

Keterangan :

$\mathrm{NCF}=$ Nilai core factor

$\mathrm{NSF} \quad=$ Nilai secondary factor

\begin{tabular}{|c|c|c|}
\hline No & Aspek & Type \\
\hline 1 & Beban Kerja & $\mathrm{CF}$ \\
\hline
\end{tabular}

\subsection{Aspek Kriteria Kepanitiaan}

Tabel 2. Aspek Penilaian 
Jurnal Riset Sistem Informasi Dan Teknik Informatika (JURASIK)

Volume 5 Nomor 2 Agustus, pp 227-236

ISSN: 2527-5771/EISSN: 2549-7839

https://tunasbangsa.ac.id/ejurnal/index.php/jurasik

\begin{tabular}{|c|l|c|}
2 & Bertanggung Jawab & CF \\
\hline 3 & Berjiwa Kepemimpinan & CF \\
\hline 4 & Bijaksana & CF \\
\hline 5 & Adil & CF \\
\hline 6 & Disiplin & CF \\
\hline 7 & Ahli dalam tulis menulis & CF \\
\hline 8 & Menguasai Akuntansi & CF \\
\hline 9 & Mampu memanajemen waktu dengan baik & CF \\
\hline 10 & Jujur & CF \\
\hline 11 & Berkomitmen & CF \\
\hline 12 & Teliti & SF \\
\hline 13 & Sehat jasmani dan rohani & SF \\
\hline 14 & Mampu berkomunikasi dengan baik & SF \\
\hline 15 & Mampu menggunakan kamera dengan baik & SF \\
\hline 16 & Memiliki SIM & SF \\
\hline 17 & Kreatif & SF \\
\hline 18 & Percaya diri & SF \\
\hline
\end{tabular}

\section{HASIL DAN PEMBAHASAN}

\subsection{Analisa Ketua}

a. Perhitungan Pemetaan Gap

Tahapan ini digunakan untuk mencari selisih antara profil pekerjaan dan profil pekerja. Pada Tabel 3 berikut merupakan perhitungan Gap yang diperoleh.

Tabel 3. Perhitungan Gap Ketua

\begin{tabular}{|c|c|c|c|c|c|c|c|c|c|}
\hline No & Nama & 1 & 2 & 3 & 4 & 5 & 6 & 7 & \multirow[t]{8}{*}{ Profil Kandidat } \\
\hline 1 & Annisa & 4 & 3 & 3 & 3 & 3 & 3 & 4 & \\
\hline 2 & Dinar & 4 & 2 & 2 & 3 & 3 & 2 & 3 & \\
\hline 3 & Nugroho & 3 & 4 & 4 & 4 & 4 & 3 & 3 & \\
\hline 4 & Fatmawati & 2 & 3 & 3 & 3 & 2 & 3 & 2 & \\
\hline 5 & Firza & 3 & 3 & 2 & 4 & 3 & 2 & 3 & \\
\hline 6 & Ardhi & 5 & 3 & 4 & 3 & 2 & 4 & 3 & \\
\hline 7 & Hanifa & 3 & 2 & 2 & 3 & 3 & 3 & 2 & \\
\hline & & 3 & 4 & 3 & 5 & 3 & 4 & 3 & Profil Ketua \\
\hline No & Nama & 1 & 2 & 3 & 4 & 5 & 6 & 7 & \multirow{8}{*}{ GAP } \\
\hline 1 & Annisa & 1 & -1 & 0 & -2 & 0 & -1 & 1 & \\
\hline 2 & Dinar & 1 & -2 & -1 & -2 & 0 & -2 & 0 & \\
\hline 3 & Nugroho & 0 & 0 & 1 & -1 & 1 & -1 & 0 & \\
\hline 4 & Fatmawati & -1 & -1 & 0 & -2 & -1 & -1 & -1 & \\
\hline 5 & Firza & 0 & -1 & -1 & -1 & 0 & -2 & 0 & \\
\hline 6 & Ardhi & 2 & -1 & 1 & -2 & -1 & 0 & 0 & \\
\hline 7 & Hanifa & 0 & -2 & -1 & -2 & 0 & -1 & -1 & \\
\hline
\end{tabular}

\section{b. Pembobotan Hasil Pemetaan Gap}

Setelah mendapatkan selisih antara profil kandidat dan profil pekerjaan yang dijadikan acuan, maka langkah berikutnya adalah memberikan nilai bobot dengan mengacu pada Tabel 1, sehingga diperoleh hasil bobot seperti pada Tabel 4 . 
Tabel 4. Pembobotan Gap Ketua

\begin{tabular}{|c|l|r|r|r|r|r|r|r|}
\hline No & \multicolumn{1}{|c|}{ Nama } & 1 & 2 & 3 & 4 & 5 & 6 & 7 \\
\hline 1 & Annisa & 4.5 & 4 & 5 & 3 & 5 & 4 & 4.5 \\
\hline 2 & Dinar & 4.5 & 3 & 4 & 3 & 5 & 3 & 5 \\
\hline 3 & Nugroho & 5 & 5 & 4.5 & 4 & 4.5 & 4 & 5 \\
\hline 4 & Fatmawati & 4 & 4 & 5 & 3 & 4 & 4 & 4 \\
\hline 5 & Firza & 5 & 4 & 4 & 4 & 5 & 3 & 5 \\
\hline 6 & Ardhi & 3.5 & 4 & 4.5 & 3 & 4 & 5 & 5 \\
\hline 7 & Hanifa & 5 & 3 & 4 & 3 & 5 & 4 & 4 \\
\hline
\end{tabular}

c. Perhitungan dan Pengelompokkan Core dan Secondary Factor

Setelah proses penentuan nilai bobot selesai dilakukan, maka langkah berikutnya adalah melakukan perhitungan dan pengelompokkan nilai untuk core dan secondary factor sehingga diperoleh hasil seperti pada Tabel 5.

Tabel 5. Perhitungan Core dan Secondary Factor Ketua

\begin{tabular}{|c|l|r|r|r|r|r|r|r|r|c|}
\hline No & \multicolumn{1}{|c|}{ Nama } & \multicolumn{1}{c|}{2} & \multicolumn{1}{c|}{3} & 4 & 5 & 6 & 7 & NCF & NSF \\
\hline 1 & Annisa & 4.5 & 4 & 5 & 3 & 5 & 4 & 4.5 & 4.25 & 4.5 \\
\hline 2 & Dinar & 4.5 & 3 & 4 & 3 & 5 & 3 & 5 & 3.75 & 5 \\
\hline 3 & Nugroho & 5 & 5 & 4.5 & 4 & 4.5 & 4 & 5 & 4.50 & 5 \\
\hline 4 & Fatmawati & 4 & 4 & 5 & 3 & 4 & 4 & 4 & 4.00 & 4 \\
\hline 5 & Firza & 5 & 4 & 4 & 4 & 5 & 3 & 5 & 4.17 & 5 \\
\hline 6 & Ardhi & 3.5 & 4 & 4.5 & 3 & 4 & 5 & 5 & 4.00 & 5 \\
\hline 7 & Hanifa & 5 & 3 & 4 & 3 & 5 & 4 & 4 & 4.00 & 4 \\
\hline
\end{tabular}

d. Penentuan Hasil Akhir/Rangking

Hasil akhir dari proses profile matching merupakan rangking dari nilai yang paling direkomendasikan ditandai dengan nilai paling tinggi. Tabel 6 menunjukkan hasil perhitungan dengan memberikan nilai $60 \%$ untuk core factor, dan $40 \%$ untuk secondary factor, sehingga diperoleh rincian perhitungan detail sebagai berikut.

Tabel 6. Hasil Akhir Perhitungan Ketua

\begin{tabular}{|c|l|r|r|l|r|}
\hline No & \multicolumn{1}{|c|}{ Nama } & NCF & NSF & HA & Rank \\
\hline 1 & Annisa & 4.25 & 4.5 & 4.35 & 4 \\
\hline 2 & Dinar & 3.75 & 5 & 4.25 & 5 \\
\hline 3 & Nugroho & 4.50 & 5 & 4.70 & 1 \\
\hline 4 & Fatmawati & 4.00 & 4 & 4.00 & 6 \\
\hline 5 & Firza & 4.17 & 5 & 4.50 & 2 \\
\hline 6 & Ardhi & 4.00 & 5 & 4.40 & 3 \\
\hline 7 & Hanifa & 4.00 & 4 & 4.00 & 7 \\
\hline
\end{tabular}




\subsection{Analisa Sekretaris}

a. Perhitungan Pemetaan Gap

Tabel 7. Perhitungan Gap Sekretaris

\begin{tabular}{|c|c|c|c|c|c|c|c|}
\hline No & Nama & 1 & 2 & 3 & 4 & 5 & \multirow[t]{8}{*}{ Profil Kandidat } \\
\hline 1 & Annisa & 4 & 3 & 3 & 5 & 3 & \\
\hline 2 & Dinar & 4 & 4 & 3 & 3 & 2 & \\
\hline 3 & Nugroho & 3 & 3 & 4 & 3 & 3 & \\
\hline 4 & Fatmawati & 2 & 5 & 3 & 5 & 4 & \\
\hline 5 & Firza & 3 & 3 & 4 & 3 & 2 & \\
\hline 6 & Ardhi & 5 & 4 & 3 & 2 & 3 & \\
\hline 7 & Hanifa & 3 & 3 & 3 & 3 & 4 & \\
\hline & & 3 & 5 & 4 & 4 & 3 & Profil Sekretaris \\
\hline No & Nama & 1 & 2 & 3 & 4 & 5 & \multirow[t]{8}{*}{ GAP } \\
\hline 1 & Annisa & 1 & -2 & -1 & 1 & 0 & \\
\hline 2 & Dinar & 1 & -1 & -1 & -1 & -1 & \\
\hline 3 & Nugroho & 0 & -2 & 0 & -1 & 0 & \\
\hline 4 & Fatmawati & -1 & 0 & -1 & 1 & 1 & \\
\hline 5 & Firza & 0 & -2 & 0 & -1 & -1 & \\
\hline 6 & Ardhi & 2 & -1 & -1 & -2 & 0 & \\
\hline 7 & Hanifa & 0 & -2 & -1 & -1 & 1 & \\
\hline
\end{tabular}

Tabel 8. Pembobotoan Gap Sekretaris

\begin{tabular}{|c|l|c|c|c|c|c|}
\hline No & Nama & 1 & 2 & 3 & 4 & 5 \\
\hline 1 & Annisa & 4.5 & 3 & 4 & 4.5 & 5 \\
\hline 2 & Dinar & 4.5 & 4 & 4 & 4 & 4 \\
\hline 3 & Nugroho & 5 & 3 & 5 & 4 & 5 \\
\hline 4 & Fatmawati & 4 & 5 & 4 & 4.5 & 4.5 \\
\hline 5 & Firza & 5 & 3 & 5 & 4 & 4 \\
\hline 6 & Ardhi & 3.5 & 4 & 4 & 3 & 5 \\
\hline 7 & Hanifa & 5 & 3 & 4 & 4 & 4.5 \\
\hline
\end{tabular}

Tabel 9. Perhitungan Core dan Secondary Factor Sekretaris

\begin{tabular}{|c|l|c|c|c|c|c|c|c|}
\hline No & \multicolumn{1}{|c|}{ Nama } & 1 & 2 & 3 & 4 & 5 & NCF & NSF \\
\hline 1 & Annisa & 4.5 & 3 & 4 & 4.5 & 5 & 3.83 & 4.75 \\
\hline 2 & Dinar & 4.5 & 4 & 4 & 4 & 4 & 4.17 & 4 \\
\hline 3 & Nugroho & 5 & 3 & 5 & 4 & 5 & 4.33 & 4.5 \\
\hline 4 & Fatmawati & 4 & 5 & 4 & 4.5 & 4.5 & 4.33 & 4.5 \\
\hline 5 & Firza & 5 & 3 & 5 & 4 & 4 & 4.33 & 4 \\
\hline 6 & Ardhi & 3.5 & 4 & 4 & 3 & 5 & 3.83 & 4 \\
\hline 7 & Hanifa & 5 & 3 & 4 & 4 & 4.5 & 4.00 & 4.25 \\
\hline
\end{tabular}

Tabel 10. Hasil Akhir Perhitungan Sekretaris

\begin{tabular}{|c|l|c|c|l|r|}
\hline No & Nama & NCF & NSF & HA & Rank \\
\hline 1 & Annisa & 3.83 & 4.75 & 4.20 & 3 \\
\hline 2 & Dinar & 4.17 & 4 & 4.10 & 5 \\
\hline
\end{tabular}


Jurnal Riset Sistem Informasi Dan Teknik Informatika (JURASIK)

Volume 5 Nomor 2 Agustus, pp 227-236

ISSN: 2527-5771/EISSN: 2549-7839

https://tunasbangsa.ac.id/ejurnal/index.php/jurasik

\begin{tabular}{|c|l|c|c|c|r|l|}
3 & Nugroho & 4.33 & 4.5 & 4.40 & 1 & Nugroho sudah menjadi Ketua \\
& Fatmawati & 4.33 & 4.5 & 4.40 & 2 & Sekretaris \\
\hline 5 & Firza & 4.33 & 4 & 4.20 & 4 & \\
\hline 6 & Ardhi & 3.83 & 4 & 3.90 & 7 & \\
\hline 7 & Hanifa & 4.00 & 4.25 & 4.10 & 6 & \\
\cline { 1 - 3 } & &
\end{tabular}

\subsection{Analisa Sie Acara}

Tabel 11. Perhitungan Gap Sie Acara

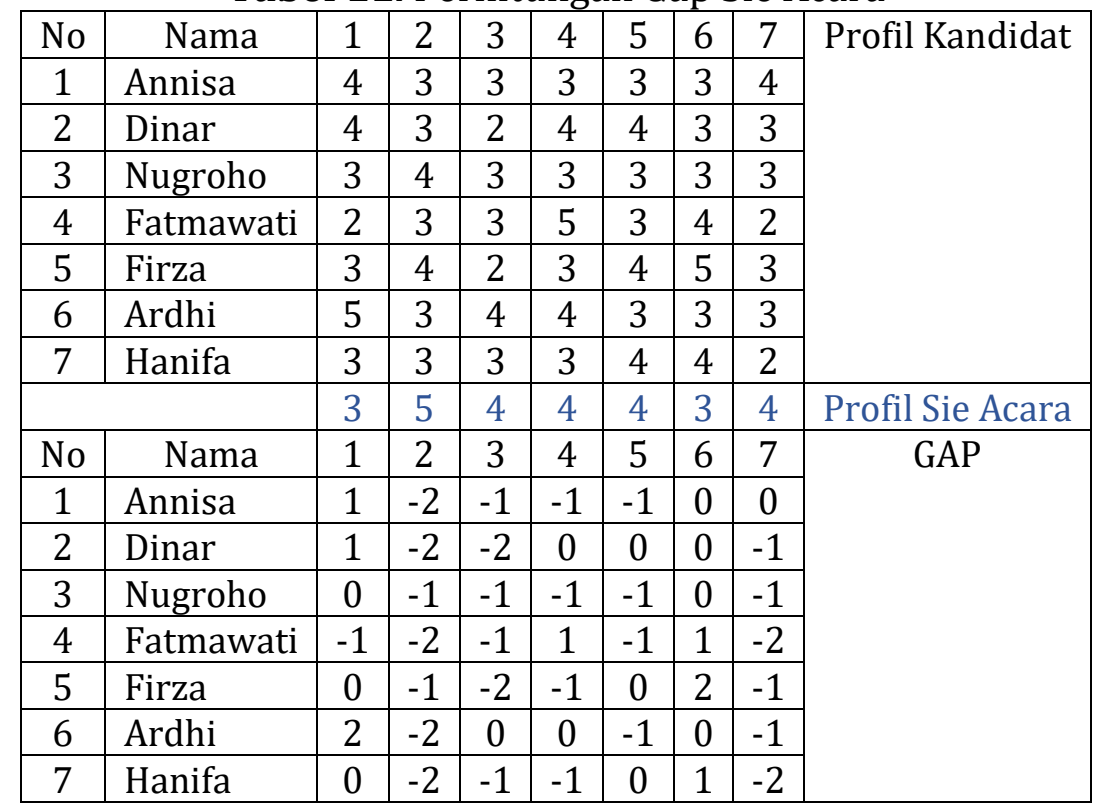

Tabel 12. Pembobotan Gap Sie Acara

\begin{tabular}{|c|l|c|c|c|c|c|c|c|}
\hline No & \multicolumn{1}{|c|}{ Nama } & 1 & 2 & 3 & 4 & 5 & 6 & 7 \\
\hline 1 & Annisa & 4.5 & 3 & 4 & 4 & 4 & 5 & 5 \\
\hline 2 & Dinar & 4.5 & 3 & 3 & 5 & 5 & 5 & 4 \\
\hline 3 & Nugroho & 5 & 4 & 4 & 4 & 4 & 5 & 4 \\
\hline 4 & Fatmawati & 4 & 3 & 4 & 4.5 & 4 & 4.5 & 3 \\
\hline 5 & Firza & 5 & 4 & 3 & 4 & 5 & 3.5 & 4 \\
\hline 6 & Ardhi & 3.5 & 3 & 5 & 5 & 4 & 5 & 4 \\
\hline 7 & Hanifa & 5 & 3 & 4 & 4 & 5 & 4.5 & 3 \\
\hline
\end{tabular}

Tabel 13. Perhitungan Core dan Secondary Factor Sie Acara

\begin{tabular}{|c|l|c|c|c|c|c|c|c|c|c|}
\hline No & Nama & 1 & 2 & 3 & 4 & 5 & 6 & 7 & NCF & NSF \\
\hline 1 & Annisa & 4.5 & 3 & 4 & 4 & 4 & 5 & 5 & 3.88 & 4.67 \\
\hline 2 & Dinar & 4.5 & 3 & 3 & 5 & 5 & 5 & 4 & 3.88 & 4.67 \\
\hline 3 & Nugroho & 5 & 4 & 4 & 4 & 4 & 5 & 4 & 4.25 & 4.33 \\
\hline 4 & Fatmawati & 4 & 3 & 4 & 4.5 & 4 & 4.5 & 3 & 3.88 & 3.83 \\
\hline 5 & Firza & 5 & 4 & 3 & 4 & 5 & 3.5 & 4 & 4.00 & 4.17 \\
\hline 6 & Ardhi & 3.5 & 3 & 5 & 5 & 4 & 5 & 4 & 4.13 & 4.33 \\
\hline 7 & Hanifa & 5 & 3 & 4 & 4 & 5 & 4.5 & 3 & 4.00 & 4.17 \\
\hline
\end{tabular}


Tabel 14. Hasil Akhir Perhitungan Sie Acara

\begin{tabular}{|c|c|c|c|c|c|c|}
\hline No & Nama & $\mathrm{NCF}$ & NSF & $\mathrm{HA}$ & Rank & \multirow{8}{*}{ Nugroho sudah menjadi Ketua } \\
\hline 1 & Annisa & 3.88 & 4.67 & 4.19 & 3 & \\
\hline 2 & Dinar & 3.88 & 4.67 & 4.19 & 4 & \\
\hline 3 & Nugroho & 4.25 & 4.33 & 4.28 & 1 & \\
\hline 4 & Fatmawati & 3.88 & 3.83 & 3.86 & 7 & \\
\hline 5 & Firza & 4.00 & 4.17 & 4.07 & 5 & \\
\hline 6 & Ardhi & 4.13 & 4.33 & 4.21 & 2 & \\
\hline 7 & Hanifa & 4.00 & 4.17 & 4.07 & 6 & \\
\hline
\end{tabular}

\subsection{Hasil}

Setelah melakukan perhitungan menggunakan Profile Matching terhadap profil kandidat dan profil pekerjaan maka diperoleh hasil yaitu pembagian pekerjaan menurut spesifikasi yang telah ditentukan. Dalam hal ini satu orang bisa memenuhi semua pekerjaan, dari perhitungan diatas Nugroho memenuhi spesifikasi dari tiga pekerjaan yang ada. Dalam kegiatan agar pekerjaan otomatis dan optimal maka pembagian jam kerja dan tangung jawab harus adil dan sesuai dengan spesifikasi. Untuk pekerjaan berikutnya akan diberikan kepada peringkat dibawahnya karena Nugroho telah memiliki pekerjaan dalam suatu kegiatan. Tujuan dari pemberian pekerjaan kepada orang lain yang berada dibawahnya adalah terlaksananya pekerjaan dengan baik karena setiap orang akan memiliki beban kerja dan tanggung jawabnya masing-masing dan tidak adanya pekerjaan ganda yang membuat pekerjaan tidak maksimal.

Tabel 15. Hasil Akhir Metode

\begin{tabular}{|l|l|}
\hline Pekerjaan & Nama \\
\hline Ketua & Nugroho \\
\hline Sekretaris & Fatmawati \\
\hline Sie Acara & Ardhi \\
\hline
\end{tabular}

\section{SIMPULAN}

Dalam penelitian ini dihasilkan perankingan dari setiap indivivdu untuk menemukan siapa yang cocok menjadi penanggung jawab dari setiap kegiatan. Sehingga penanggung jawab sesuai dengan spesifikasi yang dibutuhkan. Setiap individu juga tidak bisa melaksanakan dua pekerjaan sekaligus, hal ini menyebabkan pekerjaan menjadi tidak otomatis dan optimal maka untuk pekerjaan lainnya akan diberikan kepada peringkat dibawahnya. Dengan adanya penelitian ini diarapkan pembagian pekerjaan sesuai dengan spesifikasi yang ada sehingga individu bisa melakukan tanggung jawab dengan maksimal dan pekejaan menjadi optimal. 
Jurnal Riset Sistem Informasi Dan Teknik Informatika (JURASIK)

Volume 5 Nomor 2 Agustus, pp 227-236

ISSN: 2527-5771/EISSN: 2549-7839

https://tunasbangsa.ac.id/ejurnal/index.php/jurasik

\section{DAFTAR PUSTAKA}

[1] W. Katrina, H. J. Damanik, F. Parhusip, D. Hartama, A. P. Windarto, and A. Wanto, "C.45 Classification Rules Model for Determining Students Level of Understanding of the Subject," J. Phys. Conf. Ser., vol. 1255, no. 012005, pp. 1-7, 2019, doi: 10.1088/1742-6596/1255/1/012005.

[2] D. Hartama, A. Perdana Windarto, and A. Wanto, "The Application of Data Mining in Determining Patterns of Interest of High School Graduates," J. Phys. Conf. Ser., vol. 1339, no. 1, 2019, doi: 10.1088/1742-6596/1339/1/012042.

[3] Sudirman, A. P. Windarto, and A. Wanto, "Data mining tools | rapidminer: K-means method on clustering of rice crops by province as efforts to stabilize food crops in Indonesia," IOP Conf. Ser. Mater. Sci. Eng., vol. 420, no. 1, 2018, doi: 10.1088/1757899X/420/1/012089.

[4] Nugroho, Agung, prasetyo dan Purwanto, "Rancangan Sistem Pendukung Keputusan Penerimaan Pegawai Menggunakan Metode Profile Matching", Jurnal Eksplora Informatika, Vol. 5, No. 1, September 2015

[5] Juanita, "Sistem Pendukung Keputusan Penentuan Warga Miskin dengan Metode Simple Additive Weighing (SAW) dan Profile Matching", Universitas Sumatera Utara, Medan, 2015. 